\title{
O jornalismo de espírito público não pode ser "chapa-branca"
}

Eugênio Bucci

Jornalista, doutor em Ciências da Comunicação, é presidente da Radiobrás. Colaboradores: Carlos Henrique Knapp, especialista em Comunicação, e Isadora Grespan, jornalista - profissionais que atuam na área de Comunicação da Radiobrás.

E-mail: eugenio@radiobras.com.br

Jornalistas têm o dever de ser objetivos. Em toda e qualquer reportagem, a informação que chega ao público precisa refletir a verdade dos fatos. Todos sabemos, é claro, que não existe objetividade absoluta: tudo o que possui algum vínculo com a ação humana tem, inevitavelmente, elementos de subjetividade. Mesmo assim, somos capazes de compreender que a busca da objetividade continua sendo o norte do jornalismo comprometido com o público, do jornalismo que elege o direito à informação como seu maior valor.

É um tanto engraçado notar que, para alguns, esse princípio ainda parece trazer certo embaraço. As pessoas às vezes se assustam e perguntam se é possível ter objetividade em uma empresa pública de comunicação. A resposta, indubitavelmente, é sim.

No Brasil, a tradição na maioria das empresas públicas de comunicação faz crer que essas organizações devam atuar como linha auxiliar de propaganda do governo, como se fossem propriedades privadas dos governantes ou agências de promoção particular das pessoas dos governantes. No entanto, a cultura de compor empresas públicas de comunicação, a partir do compromisso com a objetividade jornalística e com o direito à informação, já está sendo construída neste país.

Qualquer governo verdadeiramente voltado à estruturação da democracia para todos é também beneficiário de uma comunicação jornalística pautada pela objetividade. Na democracia, a legitimidade do governo não vem da obediência e da concordância, como acontece com a comunicação dos regimes autoritários, mas da participação crítica e autônoma do cidadão.

Não há, portanto, conflito entre o jornalismo objetivo e as mais nobres intenções de um governo democrático, pois a ele interessa que uma instituição destinada a informar o público tenha credibilidade, seja digna de confiança. A informação objetiva eleva o padrão de credibilidade dessas empresas, do Estado e do governo. Ademais, ao ser mais bem informado, o cidadão se torna parte da esfera que decide no país, o que só reforça a democracia. 
Poucas práticas são mais arriscadas para a imagem de uma autoridade pública do que a ação de um jornalista que, fingindo fazer reportagem, tenta realizar propaganda dessa autoridade. Esse profissional certamente levará ao público uma informação de má qualidade. Pior, vai fazer propaganda de péssima categoria, tão ruim que surtirá o efeito de uma antipropaganda. E não há dúvida: o público percebe essas tentativas primárias de manipulação.

Não é por acaso que, nas democracias modernas, o campo das Relações Públicas de Governo e da Propaganda de Governo tornou-se especializado, não se confundindo com um outro campo, que é o de prestar informações jornalísticas objetivas ao cidadão. Tanto um quanto outro são indispensáveis, legítimos e necessários, e cada vez mais caminham separadamente e de modo transparente, para benefício de todos.

A Radiobrás é uma empresa pública regida pela lei das sociedades anônimas. Tem apenas um acionista, o Tesouro Nacional, e não gera receitas suficientes para sua própria sustentação. Por isso, é chamada corretamente de empresa dependente do Tesouro. Essa dependência em relação ao Tesouro incide sobre a definição de seu jornalismo: ele pode pretender ser objetivo, mas não é rigorosamente adequado anunciar que ele seja independente. O que se explica sem dificuldade. O conceito de independência editorial, que se firmou na ética jornalística entre o final do século XIX e o início do século XX, baseia-se na independência econômica e financeira da empresa jornalística (independência de que a Radiobrás não dispõe). Trata-se de uma concepção que nasce do jornalismo de mercado. Um veículo de comunicação privado é independente editorialmente quando o grupo que o edita é independente financeiramente. Quer dizer, quando ele não está sujeito a um anunciante em especial, a uma verba privilegiada do governo ou a um agente financiador privilegiado.

Embora a Radiobrás tenha autonomia administrativa, ela não possui independência financeira. Assim sendo, afirmar que ela oferece ao público um jornalismo independente seria uma frase sem base material. Isso, no entanto, não implica que o seu jornalismo seja direcionado para veicular versões artificialmente favoráveis a esta ou àquela autoridade. A Radiobrás não é independente financeiramente, mas, por ser uma empresa pública, tem todas as condições de oferecer ao público um jornalismo objetivo e pautado pela verdade factual.

O fato de a Radiobrás, como instituição pública, não ser uma empresa subordinada às leis do mercado, também traz vantagens e se torna uma garantia de sua qualidade editorial, e não uma limitação. Nenhum dos jornalistas da casa é requisitado a recorrer a qualquer tipo de apelação para conquistar audiência, não é chamado a fazer sensacionalismo. O jornalismo da Radiobrás tem foco no cidadão, e não em conquistar qualquer audiência a todo custo.

Sua pauta cabe em um triângulo cujos vértices são: Cidadania, Estado e Governo. Sempre que algo disser respeito à relação entre o cidadão e o Estado, entre o cidadão e o governo, ou entre o cidadão e seus direitos, é notícia.

Quando um jornalista da Radiobrás está ante uma autoridade do governo - um ministro, secretário executivo, porta-voz, ou assessor de imprensa, por 
exemplo -, ele precisa ter em mente o problema do cidadão. Se uma medida está sendo anunciada, esse repórter deve preocupar-se com a linguagem indicada para que o cidadão entenda essa notícia; ele precisa pensar, também, de que modo o que está sendo noticiado vai gerar mudanças em sua vida.

Na Radiobrás, a informação de interesse público é buscada junto a fontes autorizadas e oficiais. A Radiobrás não publica nenhuma informação em off, assim como não publica nenhuma informação cuja origem não seja explicitamente clara. O exercício da dúvida, essencial ao jornalismo, recai sobre os fatos e não sobre o interlocutor. E essa é uma marca do jornalismo de espírito público no mundo inteiro: a abordagem de boa-fé.

Notícias que, nos tempos do autoritarismo, poderiam ser consideradas desfavoráveis do ponto de vista da boa imagem do governo, agora aparecem normalmente no noticiário da Radiobrás. Essa conduta - na Radiobrás e em qualquer instituição pública de comunicação - não afeta a boa imagem de um governo democrático. Ao contrário, reforça-a, pois a melhor contribuição que o jornalismo de espírito público pode dar à sociedade é orientar seu trabalho com objetividade e foco no cidadão, para atender ao direito universal de acesso à informação de qualidade.

\section{CONHEÇA A RADIOBRÁS}

\section{Missão}

A Radiobrás é uma empresa pública de comunicação que busca veicular com objetividade informações sobre Estado, governo e vida nacional. Trabalha para universalizar o acesso à informação, direito fundamental para o exercício da cidadania.

\section{Valores}

Os valores, que expressam e sustentam a dimensão ética das ações da empresa, têm como base o respeito:

- Respeito ao caráter público de atividade que exerce, ao buscar a excelência e ao exercer a transparência interna e externa.

- Respeito à cidadania, ao assumir um compromisso permanente com a universalização do direito à informação, com a verdade e com a qualidade da informação, por meio de canal direto com o público.

- Respeito às diferenças, por meio do diálogo.

- Respeito às pessoas ao promover a felicidade no trabalho, a criatividade e a inovação.

Tendo o respeito como base, a ética da Radiobrás concretiza-se na renovação cotidiana de sua credibilidade junto à sociedade brasileira e aos funcionários da empresa. 
Os serviços da Radiobrás são oferecidos por três diferentes veículos: agência de notícias, rádio e televisão.

\section{AgÊNCIA DE NOTÍCIAS}

Agência Brasil-<http:/ /www.agenciabrasil.gov.br>: responsável pela produção das notícias veiculadas pelo sistema Radiobrás; tem por missão ser uma agência pública de notícias, de acesso livre e abordagem pluralista. Até novembro de 2004, alcançou uma média de 6,4 milhões de acessos e cerca de 4.800 matérias publicadas por mês.

Notícias: informações em tempo real sobre governo, Estado e cidadania, disponibilizadas gratuitamente para o cidadão e para a reprodução pela mídia nacional e internacional.

Sinopse: as principais informações políticas e econômicas veiculadas pelos jornais, também oferecidas gratuitamente.

Fotos: iconografia relacionada ao governo, Estado e cidadania. Igualmente são de uso livre, desde que citados a fonte e o autor.

Radioagência Nacional - <http:/ / www.radiobras.gov.br/radioagencia >: trata-se da primeira radioagência pública do País. Seu conteúdo compreende reportagens e boletins produzidos por repórteres e correspondentes, assim como matérias feitas pelas emissoras públicas parceiras, os ministérios e outras instâncias do Poder Executivo. Em operação desde outubro de 2004, ela disponibiliza a média de 65 matérias por dia, sendo realizados cerca de 250 downloads de material noticioso diariamente.

\section{RÁDIO}

Rádio Nacional de Brasília - AM (980 kHz): criada em 1958, a Rádio Nacional AM de Brasília opera 24 horas por dia em ondas médias. Sua programação pode ser dividida em dois blocos distintos, tendo como parâmetro a cobertura de seu sinal. Durante o dia, das 7 às 19 horas, a emissora transmite em 50 kW de potência cobrindo o Distrito Federal e parte da Região Centro-Oeste do Brasil. À noite, das 19 às 7 horas, opera em $300 \mathrm{~kW}$ de potência, cobrindo todo o País e parte da América Latina. A emissora comanda hoje a maior rede de rádio brasileira, composta por cerca de 185 emissoras filiadas de todos os Estados que retransmitem seus programas.

Rádio Nacional de Brasília - FM (96,1 MHz): no ar desde 1977, a emissora cobre todo o Distrito Federal e entorno. A programação, 24 horas no ar, tem em seu repertório o melhor da Música Popular Brasileira. Informação jornalística objetiva e a promoção da diversidade cultural da região completam sua grade de produção.

Rádio Nacional da Amazônia - OC $(11.780 \mathrm{kHz} / 25 \mathrm{~m}$ - $6.180 \mathrm{kHz} / 49 \mathrm{~m})$ : essa emissora de ondas curtas tem como objetivo integrar a população da Amazônia Legal à vida nacional, por meio de informação objetiva, isenta e esclarecedora, 
voltada para a realidade regional. Inaugurada em 1ํ de setembro de 1977, cobre cerca de $50 \%$ do território nacional. Sua programação vai ao ar diariamente, das cinco da manhã até a meia-noite, e pode ser ouvida por aproximadamente 60 milhões de habitantes nos Estados da Região Norte, além de Maranhão, Piauí, Bahia, Minas Gerais, Mato Grosso e Goiás.

A OC apresenta programas jornalísticos, educativos e culturais; serviços de utilidade pública e um serviço de mensagens de pessoa a pessoa, muito útil e popular em uma região tão vasta e de densidade demográfica tão baixa. Divulga, também, informações sobre a vida cotidiana das comunidades locais. Parte da programação é elaborada com base nas informações recebidas por cartas e telefonemas de ouvintes - entre janeiro e setembro de 2004, foram mais de 19 mil cartas recebidas.

Rádio Nacional do Rio de Janeiro - AM (1.120 kHz): patrimônio histórico e cultural brasileiro, a Rádio Nacional foi o berço do nosso rádio, a precursora do radioteatro e dos programas de auditório. Microfone de Jamelão, Chico Alves, Emilinha Borba, Cauby Peixoto e tantas outras glórias da canção popular, deteve a liderança absoluta de audiência nas décadas de 1940 e 1950, desempenhando um papel cultural fundamental na integração da sociedade brasileira.

Decadente e relegada ao abandono nas últimas décadas, foi recuperada a partir de um convênio firmado entre a Radiobrás e a Petrobras e reinaugurada pelo Presidente da República em junho de 2004. Os estúdios, instalados no famoso edifício A Noite, foram restaurados, o auditório foi totalmente reformado e todo o equipamento, renovado. A Nacional voltou ao ar com uma programação calcada em boa música brasileira, programas ao vivo e noticiário de qualidade.

Rádio Nacional do Brasil - RNB (9.665 kHz/31m): em 1958, dois anos antes da inauguração de Brasília, o Governo Federal criou essa emissora para servir de meio de comunicação com os trabalhadores que construíam a nova capital. As transmissões da Rádio Nacional do Brasil duraram até a década de 1990.

No dia $1^{\circ}$ de agosto de 2003, antecedendo a visita do presidente Luiz Inácio Lula da Silva à África, a Radiobrás recolocou a emissora no ar, com uma programação diária de duas horas, dirigida aos países africanos de língua portuguesa. Ela visa principalmente estreitar as relações do nosso país com as demais nações que formam a Comunidade dos Países da Língua Portuguesa (CPLP).

Rádio Justiça - <http://www.radiojustica.gov.br $>$ - FM (91,1 $\mathrm{mHz})$ : instalada em Brasília e operada pela Radiobrás, numa potência de $5 \mathrm{~kW}$, apresenta noticiários sobre o Poder Judiciário. Resultado de uma parceria entre essa empresa e o Supremo Tribunal Federal (STF), a emissora estreou em maio de 2004 com o objetivo de levar aos ouvintes conhecimentos acerca do Poder Judiciário em uma linguagem acessível.

\section{TELEVISÃo}

$\mathrm{NBr}$ - TV do Governo Federal: é o resultado de investimentos em novas tecnologias que permitiram a inserção da emissora no campo da televisão por 
assinatura e no sistema de Satélite B1. O principal objetivo dessa rede é informar sobre ações econômicas, políticas e sociais do Poder Executivo, além de difundir programas e serviços de utilidade pública. Sua programação é prioritariamente jornalística e inclui transmissões de eventos e pronunciamentos oficiais, campanhas institucionais e documentários.

TV Nacional: sintonizada no canal dois, a TV Nacional é a emissora de Brasília que pertence à Rede Pública de Televisão Brasileira, integrada pelas 20 emissoras que formam a Associação Brasileira das Emissoras Públicas Educativas e Culturais (Abepec). Sua programação é composta de jornalismo com foco no cidadão e por programas educativos, culturais, infantis, de auditório, entrevistas e documentários.

Resumo: Baseado em documentos internos da Radiobrás para a orientação jornalística de suas equipes, este artigo - além de apresentar toda a estrutura de operação e os diversos serviços prestados pelos canais de comunicação da Radiobrás - discute as questões de valor e compromisso com o interlocutor, fundamentais aos processos responsáveis de comunicação, independentemente de sua esfera de produção: pública (financiada pelo governo) ou privada (financeiramente autônoma). A Radiobrás, como instituição pública de prestação de serviços, prima e garante a qualidade de sua produção editorial. Os jornalistas da casa não precisam recorrer a qualquer tipo de apelação mercadológica ou sensacionalismo para conquistar audiência. O jornalismo da Radiobrás tem foco no cidadão, e não no mercado. O tripé Cidadania, Estado e Governo sustenta a pauta da Radiobrás. A linguagem é trabalhada para que o cidadão entenda a notícia e perceba como aquele fato impacta e gera mudanças em sua vida.

Palavras-chave: comunicação, jornalismo, produção de notícia, ética, Radiobrás.
Abstract: Founded upon Radiobras' internal documents for the journalistic orientation of its teams, this article - besides presenting all the operational structure and the several services offered by the company's communication channels - also discusses the issues of value and commitment with the interlocutor, which are fundamental in responsible communication processes, independently of its range of production: the public sector (financed by government) or the private one (financially autonomous). As a Government-owned services company, Radiobras stands out for and guarantees its editorial production quality. The company's journalists do not need to evoke any kind of marketing expedient or sensationalism to conquer audience. The journalism of Radiobras focuses on the citizen not on the market. The tripod Citizenship, State and Government stands its agenda. Language is worked for allowing the citizen to understand the news and realize how a determined fact impacts and generates changes in his life.

Keywords: communication, journalism, news production, ethics, Radiobras. 